\title{
Balloon Laryngoplasty for Subglottic Stenosis Caused by Orotracheal Intubation at a Tertiary Care Pediatric Hospital
}

\author{
Melissa Gomes Ameloti Avelino ${ }^{1}$ Edson Junior de Melo Fernandes ${ }^{1}$ \\ ${ }^{1}$ Department of Otorhinolaryngology Surgery, Universidade Federal \\ de Goiás, Clinical Hospital, Av. Primeira Avenida, Goiânia, GO, Brazil \\ Address for correspondence Edson Junior de Melo Fernandes, ENT, \\ Department of Otorhinolaryngology Surgery, Universidade Federal de \\ Goiás Clinical Hospital, Av. Primeira Avenida, Goiânia, GO, Brazil \\ Int Arch Otorhinolaryngol 2014;18:39-42. \\ (e-mail: ed_2009@hotmail.com).
}

\begin{abstract}
Introduction In recent years, there has been a reduction in mortality rates in neonatal intensive care units (NICUs) due to the impact of modern technological advances in the perinatal field. As a consequence, prolonged orotracheal intubation is used more frequently, and there has been an increase in acquired subglottic stenosis (SGS) in children. Subglottic stenosis is a narrowing of the endolarynx and one of the most common causes of stridor and respiratory distress in children. The laryngoplasty balloon has proven effective in dealing with stenosis both as primary and secondary treatments, after open surgery, with the added advantage of being less invasive and not requiring external access.

Materials and Methods This study involved children from pediatric intensive care units or NICUs suffering from respiratory distress and who presented an endoscopic diagnosis of Myer and Cotton grade I to III SGS. These patients underwent balloon laryngoplasty with different numbers of interventions depending on the response in each individual case.

Results All the patients responded satisfactorily to the balloon laryngoplasty. None required tracheostomy after treatment and all remained asymptomatic even after 6-month follow-up. One patient required just 1 dilation, 4 required 2, 3 underwent the procedure 3 times, and another had 5 dilations.

Keywords Conclusion The experience presented here is that of balloon laryngoplasty post-

- larynx

- intubation orotracheal intubation SGS with very satisfactory results at a tertiary care pediatric

- pediatrics

- laryngoplasty hospital. Although the number of patients is limited, our incidence corroborates other studies that demonstrate the efficacy and safety of balloon dilatation in the treatment of SGS.
\end{abstract}

\section{Introduction}

Subglottic stenosis is a narrowing of the endolarynx and one of the most common causes of stridor and respiratory distress in children. Children are most commonly affected because the endolarynx is the narrowest part of the airway at this age.
There has been a recent reduction in mortality rates in neonatal intensive care units (NICUs) due to the impact of modern technological advances in the perinatal field. ${ }^{1}$ As a consequence, prolonged orotracheal intubation (OTI) is more frequently used, and, in contrast to adults where tracheostomy has been well established for such cases, it is a complex received

May 1, 2013

accepted

August 4, 2013
DOI http://dx.doi.org/

10.1055/s-0033-1358577. ISSN 1809-9777.
Copyright ( $\odot 2014$ by Thieme Publicações License terms Ltda, Rio de Janeiro, Brazil

() (1) $\ominus \circledast$ 
procedure for this pediatric age group. ${ }^{2}$ As a result, an increase in acquired SGS in children has emerged.

Subglottic stenosis can be either congenital or acquired. In acquired cases, it is responsible for $90 \%$ of subglottic narrowing in children and is usually secondary to prolonged tracheal intubation. $^{3}$

Factors leading to OTI SGS include duration of intubation, inadequately sized tracheal tube, multiple intubations, cuff pressure, movement of the orotracheal tube, respiratory infections, and others. As there is usually a combination of these factors, even intubations for short periods can cause some degree of stenosis. ${ }^{3}$

Different treatment options include tracheostomy, open surgery, and minimally invasive surgery. However, the management of these patients is still a challenge for the otorhinolaryngologist. ${ }^{4}$

The balloon dilatation procedure has been used to treat laryngeal or tracheal stenosis in children as early as the 1980s and has shown encouraging results. ${ }^{5}$ Studies describe satisfactory results especially in cases of precociously treated acquired stenosis.

The aim of this study is to present the experience of a tertiary care pediatric hospital in the management of acute SGS, secondary to OTI, through balloon laryngoplasty and to assess the number of dilatations needed and the success of this technique as a primary treatment.

\section{Materials and Methods}

The study included nine children from the pediatric intensive care unit and/or NICU at the Children's Hospital in Goiânia (-Table 1). All presented with respiratory distress and/or had had a tracheotomy between May 2010 and July 2012, and a diagnosis of Myer and Cotton grade I to III SGS had been confirmed by endoscopy (- Table 2). ${ }^{6}$ All these children
Table 1 Myer and Cotton subglottic stenosis grading

\begin{tabular}{|l|}
\hline Grade I = up to $50 \%$ obstruction \\
\hline Grade II = from 51 to $70 \%$ obstruction \\
\hline Grade III = from 71 to $99 \%$ obstruction \\
\hline Grade IV = no detectable lumen \\
\hline
\end{tabular}

underwent flexible bronchoscopy 3.2 and 0-degree 2.7-mm or 4-mm rigid endoscopy (-Fig. 1). The balloon used was the Acclarent (Acclarent, INC, Menlo Park, USA) according to age, with the gauge for pressure control (-Figs. 2 and $\mathbf{3}$ ).

\section{Inclusion Criteria}

1. Children from the pediatric intensive care unit and neonatal respiratory distress or tracheostomy under 1 month of evolution

2. Myer and Cotton diagnosis of grade I to III SGS confirmed by endoscopy

3. Children undergoing laryngoplasty by balloon by the same otolaryngologist with minimum follow-up of 6 months

To meet the inclusion criterion, children had to have acute stenosis, which excluded those with delayed evolution.

\section{Exclusion Criteria}

1. Children with SGS with more than a month of evolution

2. Children who were submitted to other expansions that were not with balloon

3. Children who had participated in other procedures on the larynx

Table 2 Patient profiles, their ages, evolution time, degree, number of dilatations, interval between dilatations, and evolution

\begin{tabular}{|c|c|c|c|c|c|c|c|}
\hline Age & Cause & Sex & Degree & $\begin{array}{l}\text { Dilatations } \\
(n)\end{array}$ & $\begin{array}{l}\text { Interval } \\
\text { (d) }\end{array}$ & Post-OTI & Tracheostomy \\
\hline $1-3 \mathrm{mo}$ & Prolonged OTI & Female & II-III & 2 & 15 & No & No \\
\hline $8 \mathrm{mo}$ & Prolonged OTI & Male & III & 3 & 15,15 , and 21 & $\begin{array}{l}\text { Tracheostomy } \\
\text { removed }\end{array}$ & Yes \\
\hline $60 \mathrm{~d}$ & Prolonged OTI & Male & II (double) & 2 & 21 & No & No \\
\hline $35 d$ & Prolonged OTI & Female & III & 5 & $15,21,15,15,21$ & $\begin{array}{l}\text { Tracheostomy } \\
\text { removed } \\
\text { after third dilation; } \\
\text { residual stenosis } \\
\text { grade I (asymptomatic) }\end{array}$ & Yes \\
\hline $45 d$ & Prolonged OTI & Female & II & 1 & & No & No \\
\hline $1-4 \mathrm{mo}$ & Prolonged OTI & Female & II & 2 & 15 & Tracheostomy removed & Yes \\
\hline $3 \mathrm{mo}$ & Prolonged OTI & Male & III & 3 & 15 & No & No \\
\hline $1 \mathrm{mo}$ & Prolonged OTI & Male & II & 2 & 15 & No & \\
\hline $6 \mathrm{mo}$ & Prolonged OTI & Female & II-III & 3 & $15,21,15$ & No & No \\
\hline
\end{tabular}

Abbreviation: OTI, orotracheal intubation. 


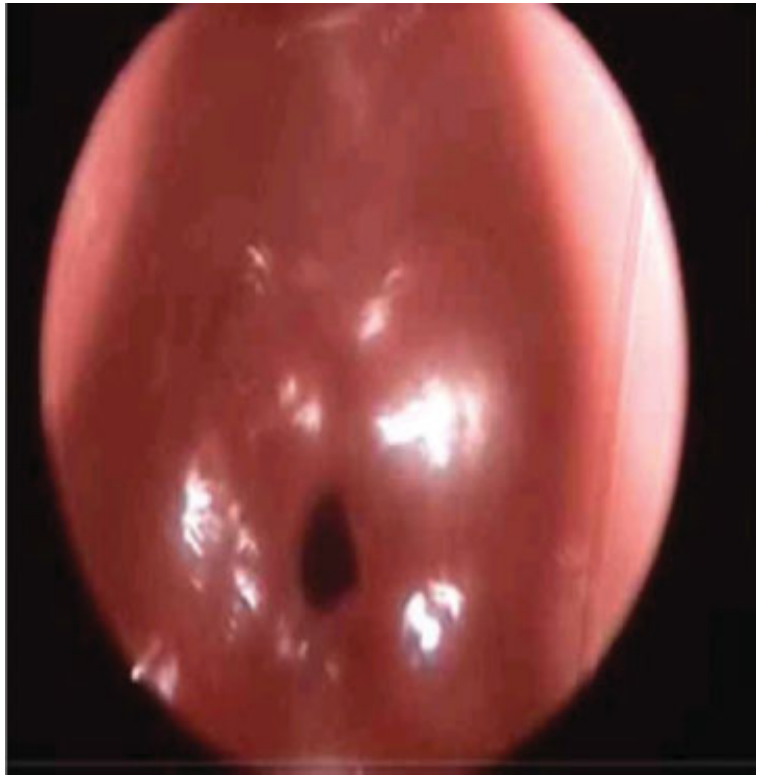

Fig. 1 Laryngoscopy showing stenosis grade III.

As exclusion criteria, the maximum length of time considered for the evolution of stenosis, that is, extubation failures and/ or tracheostomy, had to be less than 30 days (considered acute stenosis), to exclude those patients with delayed stenosis. And the minimum follow-up period after becoming asymptomatic was 6 months.

This research was analyzed and approved by the Research Ethics Committee of the Institution and was approved by the ethics committee of the Children's Hospital number 001/ 2011.

No consent was necessary because the study was chart review and assessment of children with subglottic stenosis who underwent balloon laryngoplasty by the same otolaryngologist in the period May 2010 to June 2012.

Statistical analyses were not performed due to the small number of subjects, so we chose to describe the results.

\section{Results}

- Table 1 shows the profiles of these patients, including their ages, evolution time, degree of stenosis, number of dilata-



Fig. 2 Laryngoscopy during balloon dilatation.

tions, interval between dilatations, and evolution. In all nine patients, stenosis was caused by prolonged tracheal intubation.

There was little homogeneity in this group of patients, as shown in - Table 1. Two patients had been tracheostomized at another facility and referred for this procedure, and at the moment of endoscopy, one required tracheostomy for dilatation. No serious complications were noticed during intra- or postoperative treatment of these patients.

All responded satisfactorily to balloon laryngoplasty, none required tracheostomy after the treatment, and all remained asymptomatic even after a 6-month follow-up. One patient required just 1 dilation, 4 needed 2, 3 underwent the procedure 3 times, and another had 5 dilatations. One of the patients who underwent the procedure 3 times had residual stenosis grade I stenosis, but was totally asymptomatic.

\section{Discussion}

Our study corroborates an increase in acquired SGS in children as a result of prolonged tracheal intubation associated with increased survival in NICUs. ${ }^{1}$ Despite the small number of patients, this incidence corroborates other studies that
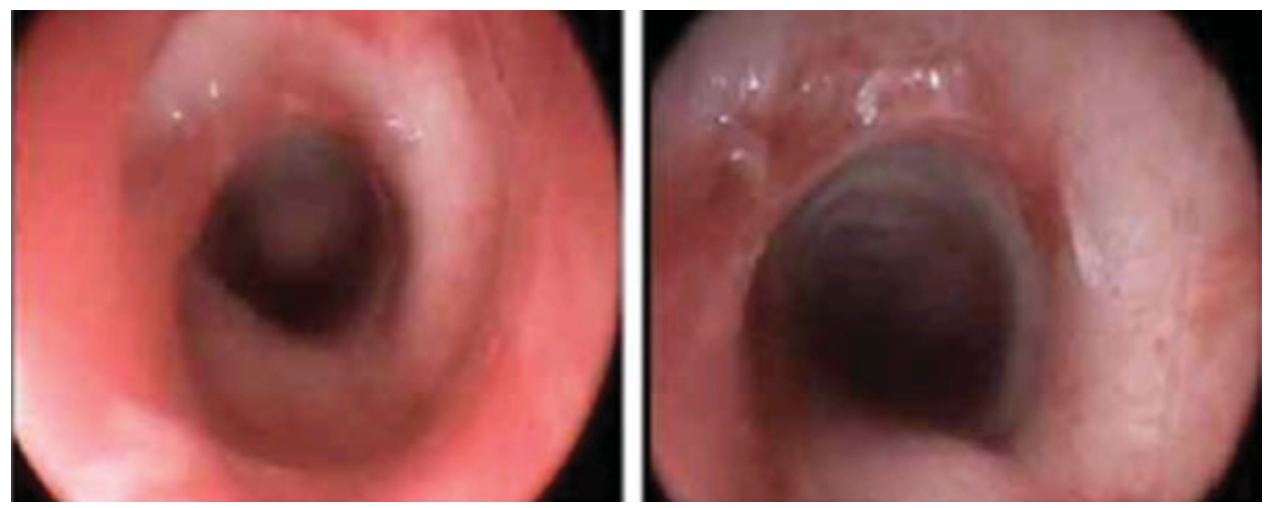

Fig. 3 Previous image and 15 days after balloon dilatation. 
have shown the efficacy and safety of balloon dilatation in the treatment of SGS. It must be stressed these were patients with recent SGS, that is, in a still active inflammatory process. This justifies such satisfactory results and also has been shown in other studies in the literature. ${ }^{7}$

Advantages of the endoscopic technique using a balloon include the application of radial force to the stenosis, the absence of shearing force, the reduction of both glottic trauma and the chances of restenosis, and, finally, low complication rates. The use of different-sized balloons and controlled pressure also collaborated to bring about these results. $^{6-9}$

The group of patients was heterogeneous, and subjects varied in age, degree of stenosis, and clinical condition, which justified the variation in the frequency and interval of dilatations. In the literature, the number of dilatations varies and some authors describe up to seven dilatations before achieving success, but most accept that up to three dilatations are necessary to avoid failure.

Four of the nine patients (44.44\%) required two dilatations before responding. In our research, we achieved success in $100 \%$ of cases, although the literature shows a success rate of 70 to $80 \%$. Our patients presented stenoses ranging from recent to a maximum of 30 days' evolution, all secondary to prolonged intubation, but there was no difference in outcome between these patients. This reinforces the use of balloon dilatation especially for acute cases but also for cases of wellestablished stenoses. Such patients should ideally be treated as early as possible, in the first extubation failures in ICUs, but this does not always happen. It would be an excellent alternative to tracheostomy in such patients. Our study corroborates the fact that the use of the balloon has satisfactory results even in cases of $\sim 30$ days' evolution.

From this study, it could be concluded that laryngoplasty with a vascular balloon was effective and complication free for acquired SGS, with up to 30 days' evolution.

\section{References}

1 Gould JB, Benitz WE, Liu H. Mortality and time to death in very low birth weight infants: California, 1987 and 1993. Pediatrics 2000; 105(3):E37

2 Fraga JC, Souza JC, Kruel J. Pediatric tracheostomy. J Pediatr (Rio J) 2009;85(2):97-103

3 Fraga JC, Nogueira A, Palombini BC, Fraga JCS. Estenose Subglótica em Crianças. Rev Bras Otorhinolaringol 1994;60(1):35-38

4 Hebra A, Powell DD, Smith CD, Othersen HB Jr. Balloon tracheoplasty in children: results of a 15-year experience. J Pediatr Surg 1991;26(8):957-961

5 Myer CM III, O'Connor DM, Cotton RT. Proposed grading system for subglottic stenosis based on endotracheal tube sizes. Ann Otol Rhinol Laryngol 1994;103(4 Pt 1):319-323

6 Schweiger C, Smith MM, Kuhl G, Manica D, Marostica PJ. Balloon laryngoplasty in children with acute subglottic stenosis: experience of a tertiary-care hospital. Braz J Otorhinolaryngol 2011; 77(6):711-715

7 Rutter MJ, Cohen AP, de Alarcon A. Endoscopic airway management in children. Curr Opin Otolaryngol Head Neck Surg 2008; 16(6):525-529

8 Choi SS, Zalzal GH. Changing trends in neonatal subglottic stenosis. Otolaryngol Head Neck Surg 2000;122(1):61-63

9 Filho JA X, Nakanishi M, Montovani JC. Pediatric Laryngeal Stenosis. Int Arch Otorhinolaryngol 2002;6(1):181 